Keio J. Med. 28: 121-130, 1979

\title{
STUDIES ON THE DIFFERENCE OF LYMPHATIC ABSORPTION BETWEEN SATURATED AND UNSATURATED LONG CHAIN FATTY ACIDS IN RATS
}

\section{- PARTICULARLY IN REFERENCE WITH THE EFFECT OF PUROMYCIN AND COLCHICINE -}

\author{
SOICHIRO MIURA, HITOSHI ASAKURA, TETSUO MORISHITA, \\ HIROSHI NAGATA, MAMORU MIYAIRI and \\ MASAHARU TSUCHIYA \\ Department of Internal Medicine, School of Medicine, \\ Keio University, Tokyo, Japan
}

(Received for Publication, September 26, 1979)

\begin{abstract}
The present studies were carried out to assess the metabolic differences between saturated and unsaturated long chain fatty acids in the process of lipid absorption and transportation to lymphatics. Male Wistar rats provided with intestinal lymph fistula were used for this experiment. Mixed micellar solutions of linoleic acid (18-carbon, unsaturated) or palmitic acid (16-carbon, saturated) were administered intraduodenally with labelled fatty acids ([1-14 C] linoleate or $[1-14 \mathrm{C}]$ palmitate) and absorbed fats were determined as the values for radioactivity of these two fatty acids found in intestinal lymph.

The absorption and transportation of linoleic acid into intestinal lymph exceeded those of palmitic acid. Puromycin, an inhibitor of protein synthesis resulting in the block of lipoprotein formation of intestinal absorptive cells, decreased the lymphatic absorption of linoleic acid, whereas not significantly decreased that of palmitic acid. It is conceivable that puromycin will mainly inhibit the formation of chylomicron rich lipoprotein from linoleic acid and that the phase of lipoprotein formation will be atttributable to the difference of absorption of these two long chain fatty acids. Colchicine, an inhibitor of microtubular function of intestinal cells which may block the release of synthesized lipoprotein out of cells, caused a delayed and decreased lymphatic absorption and transportation of palmitic acid as well as linoleic acid. Therefore we considered that there was no significant difference between two fatty acids in the phase of lipoprotein secretion.
\end{abstract}




\section{INTRODUCTION}

It has been known ${ }^{1}$ that long chain fatty acid absorbed from the intestinal lumen to intestinal epithelial cells is transported to intestinal lymphatics after the several processes in absorptive cells such as resynthesis of triglyceride and lipoprotein formation. In recent years the progress of jejunal fiberscopy make it clear that ${ }^{2,3}$ in many small intestinal diseases we can see such a characteristic findings as white villi or scattered white spots on jejunum which may correspond to the disturbance of transportation of lipid into lymphatics. The different site of blockade in the process of lipid transportation from intestinal lumen to lymphatics is now to become known ${ }^{4,5,6,7}$ in these diseases by the use of drugs which cause similar diseased condition in animals. On the other hand, the decreased rate of unsaturated fatty acid such as linoleic acid or arachidoic acid is $\mathrm{ob}$ served $^{8}$ in fatty acid composition of plasma lipid taken from patients with malabsorption in fasting state. This observation raises the possibility that in patients with malabsorption the absorption of unsaturated fatty acid from diseased bowel is affected more severely than the saturated one. Actually, several reports ${ }^{9,10}$ have suggested the differences in the intestinal absorption of saturated and unsaturated long chain fatty acid. However, little is known about the exact site of difference in the process of absorption and transportation to lymphatics between unsaturated and saturated long chain fatty acid. We therefore tried to assess the effect of different site of block in absorptive cells on lymphatic absorption of saturated and unsaturated fatty acid by the use of puromycin, ${ }^{11}$ an inhibitor of protein synthesis in absorptive cells and colchicine, ${ }^{7}$ an inhibitor of microtubular function.

\section{MATERIALS AND METHODS}

MATERIALS: Male Wistar rats weighing 350 to $400 \mathrm{~g}$ were used for the experiments. $\left[1-{ }^{14} \mathrm{C}\right]$ linoleic acid and $\left[1^{14} \mathrm{C}\right]$ palmitic acid were purchased from New England Nuclear (Boston, Mass.; purity 99\%). Linoleic acid (99\% pure) and palmitic acid (99\% pure), monoolein (99\% pure), and sodium taurocholate were obtained from Nakarai Chemical Co. (Tokyo, Japan). Puromycin (Lot No. 4415) was obtained from ICN pharmaceuticals Inc. Life Sciences Group (Cleveland). Colchicine was obtained from Sigma Chemical Co. (St. Louis, Mo.).

OPERATIVE PROCEDURE OF LYMPH FISTULA ANIMALS: After intraperitoneal pentobarbital anesthesia $(50 \mathrm{mg} / \mathrm{kg}$ of body weight), the main mesenteric lymphatic duct near the cisterna chyli was cannulated to collect intestinal lymph continuously. The duodenum was also cannulated for the administration of the micellar solutions. Animals were kept in Bollman's cage ${ }^{12}$ after 


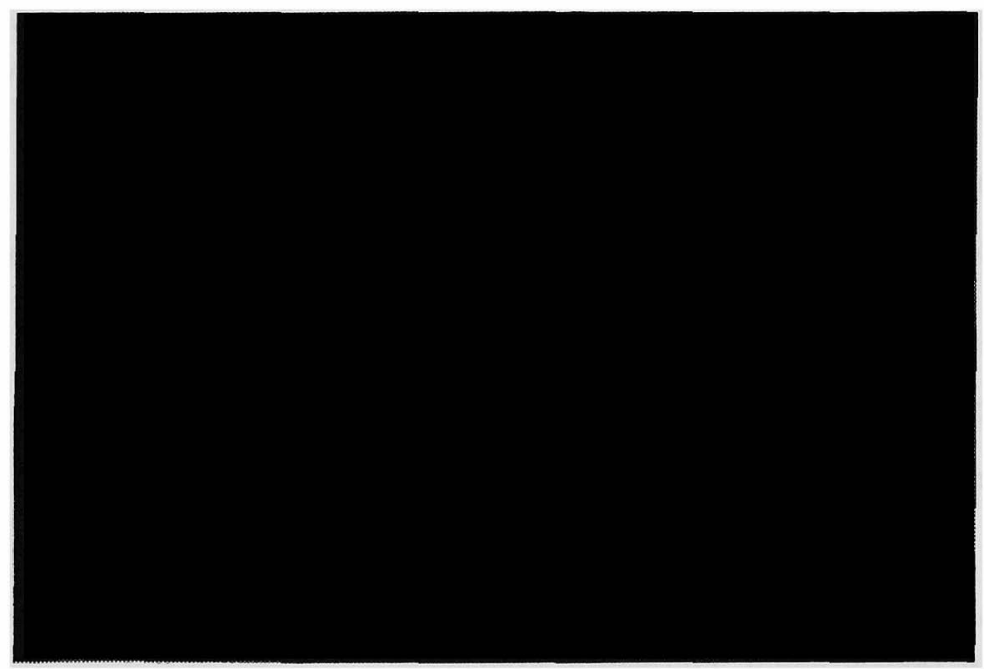

Fig. 1 A lymph fistula rat in the Bollman's cage.

the operation (Fig. 1). Normal saline was given intraduodenally $2.4 \mathrm{ml} / \mathrm{hr}$ in order to maintain a lymph flow to the end of the experiment. All animals were studied $16-20 \mathrm{hr}$ after the surgery.

PREPARATION AND ADMINISTRATION OF MIXED MICELLES: Mixed micellar solutions were prepared by drying down benzene solutions of fatty acid and monoglyceride on a evaporator and redissolving the lipid in $40 \mathrm{mM}$ taurocholate as described by Johnston and Borgström. ${ }^{13}$ This solution was then diluted with an equal volume of $0.15 \mathrm{M}$ saline-0.1 $\mathrm{M}$ phosphate buffer $\mathrm{pH} 7.0$ $(5: 1, \mathrm{v} / \mathrm{v})$, and the $\mathrm{pH}$ was adjusted to 7.4 by the addition of $1 \mathrm{~N}$ sodium hydroxide. The final concentration of the micellar solution were; taurocholate $20 \mathrm{mM}$, linoleic acid or palmitic acid $19.2 \mathrm{mM}$, and monoolein $9.6 \mathrm{mM}$. Five milliters of mixed micellar solutions containing tracer quantities of labeled fatty acid $\left(\left[1-{ }^{14} \mathrm{C}\right]\right.$ linoleate in case of linoleic acid micelles, or $\left[{ }^{1-14} \mathrm{C}\right]$ palmitate in case of palmitic acid micelles) were infused into the duodenum over a $30 \mathrm{~min}$ period to control and puromycin or colchicine-treated animals. Over the next $30 \mathrm{~min}$ no fluid were administered. Begining at $60 \mathrm{~min}$ a second infusion of $5 \mathrm{ml}$ of mixed micelles, containing no labeled fatty acid, was commenced.

\section{ADMINISTRATION OF PUROMYCIN :}

Puromycin $2 \mathrm{mg} / \mathrm{ml}$, was dissolved in $0.15 \mathrm{M} \mathrm{NaCl}-0.04 \mathrm{M}$ phosphate buffer pH 7.4 and administered via the indwelling intraperitoneal cannula continuously. 
Before the administration of mixed micelles, $2.5 \mathrm{mg}$ was given each hour for $4 \mathrm{hr}$ of infusion. After the administration of mixed micelles, $2.5 \mathrm{mg}$ was given each hour for $4 \mathrm{hr}$, then $1 \mathrm{mg}$ each hour until the end of the experiment.

\section{ADMINISTRATION OF COLCHICINE :}

Colchicine was dissolved in $0.9 \% \mathrm{NaCl}$ and injected intraperitoneally in a dose of $5 \mathrm{mg} / \mathrm{kg}$ of body weight, $2 \mathrm{hr}$ before the administration of mixed micellar solution to lymph-fistula rats.

\section{ANALYSIS OF LYMPH SAMPLES :}

Lymph samples were collected at halfhourly or hourly intervals into ice chilled heparinized tubes. Lymph samples were assayed for radioactivity by adding $0.3 \mathrm{ml}$ of lymph to $12 \mathrm{ml}$ of a scintillation solution Aquasol 2(New England Nuclear, Boston Mass.). Assays for radioactivity were carried out in a Beckman LS-230 liquid scintillation system.

\section{RESULTS}

There is a significant difference between saturated (palmitic acid, 16-carbon) and unsaturated (linoleic acid, 18-carbon) long chain fatty acid in the lymphatic absorption after the administration of mixed micelles. In Fig. 2 are shown the values for radioactivity of these two fatty acids found in the intestinal lymph as percentage of that administered. In animals which was given linoleic acid micelles, more than $87 \%$ of the administered $\left[1{ }^{14} \mathrm{C}\right]$ linoleic acid was appeared in intestinal lymph over the $6 \mathrm{hr}$ period after the administration of lipid. In contrast, $\left[1-{ }^{14} \mathrm{C}\right]$ palmitic acid administered with palmitic acid micelles showed a smaller amount of lymphatic appearance of radioactivity with only $68 \%$ of ${ }^{14} \mathrm{C}$ radioactivity appearing by $6 \mathrm{hr}$.

In puromycin-treated animals, an inhibition of lymphatic absorption of linoleic acid was observed (Fig. 3). In control animals, more than $66 \%$ of the administered radioactivity of linoleic acid appeared in lymph with the first 90 min after lipid administration. Puromycin-treated animals, however, demonstrated a decreased appearance of radioactivity of linoleic acid in lymph with only $47 \%$ of administered lipid appearing by the same hour $(0.001<\mathrm{P}<0.005$, $t=4.63$ ). There was no delayed peak of absorption of linoleic acid in puromycintreated animals. The total recovery of administered $[1-14 \mathrm{C}]$ linoleic acid over the $6 \mathrm{hr}$ period was reduced in puromycin-treated animals to $61 \%$ compared with $87 \%$ in control animals $(P<0.001, t=5.82)$. In case of palmitic acid absorption, however, the prior administration of puromycin was not associated with a sig- 


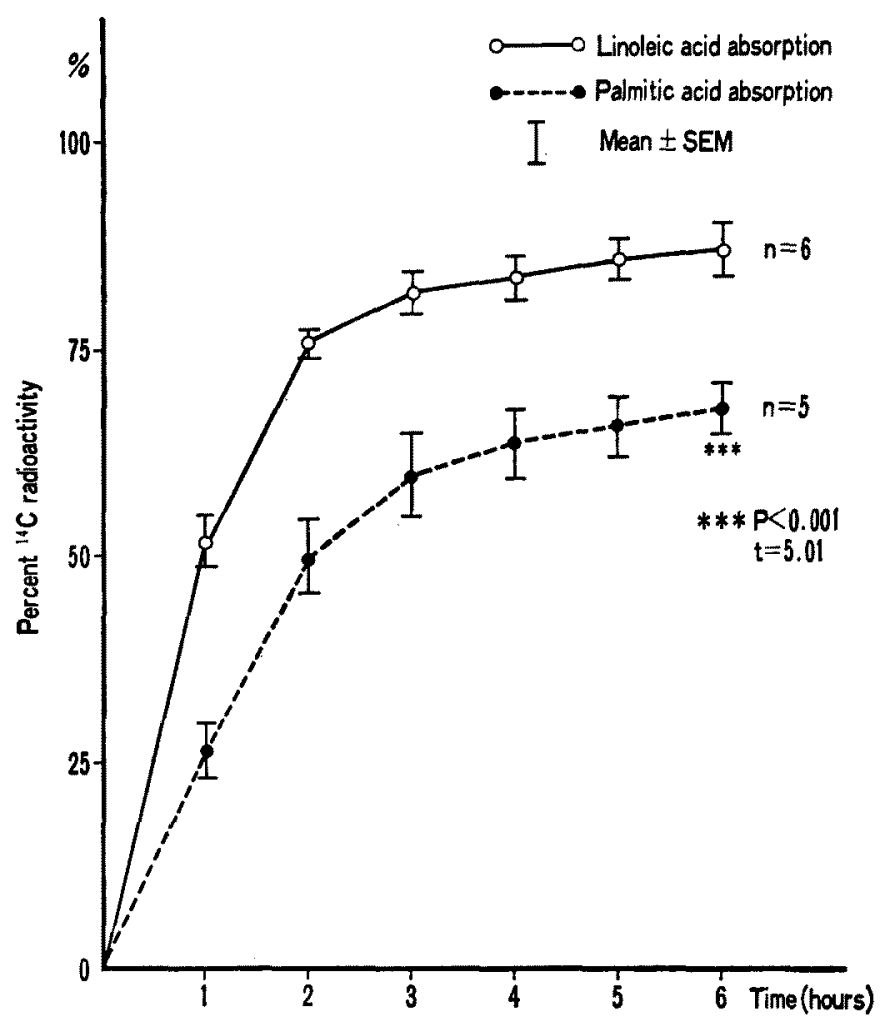

Fig. 2 Lymphatic absorption of [1-14C] linoleic acid and [1-14C] palmitic acid. Mixed micellar solutions of labeled fatty acids were administered intraduodenally to lymph fistula animals. Lymph radioactivity was determined in lymph samples at intervals over a $6 \mathrm{hr}$ period.

nificant decrease in the lymphatic appearance of intraduodenally administered $\left[1-{ }^{14} \mathrm{C}\right]$ palmitic acid. The total recovery of administered $\left[1-{ }^{14} \mathrm{C}\right]$ palmitic acid over the $6 \mathrm{hr}$ period was $65 \%$ and was not significantly different from $68 \%$ in control animals.

The effect of colchicine on lymphatic absorption of linoleic acid and palmitic acid was summarized as shown in Fig. 4. The administration of colchicine was associated with a delay as well as decrease in the lymphatic appearance of intraduodenally administered two kind of labeled fatty acids. Colchicine-treated animals showed an appearance of $19 \%$ of administered $\left[1^{14} \mathrm{C}\right]$ linoleic acid in lymph by $90 \mathrm{~min}$, whereas control animals showed $66 \% \quad(P<0.001, t=24.58)$. 


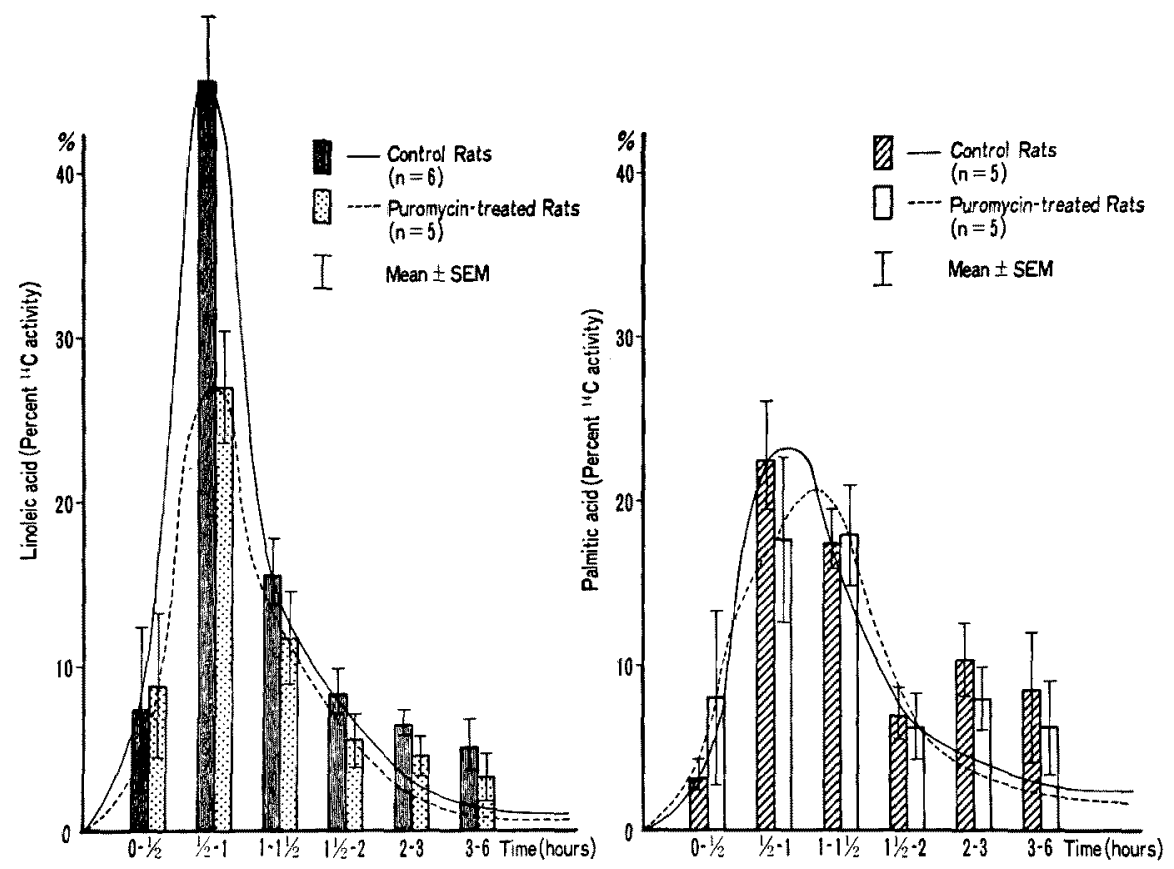

Fig. 3 Effect of puromycin on the lymphatic absorption of [1-14 C]linoleic acid (left half) and $\left[1{ }^{14} \mathrm{C}\right]$ palmitic acid (right half). Puromycin was administered intraperitoneally continuously in a dose of $2.5 \mathrm{mg} / \mathrm{hr}$ from $4 \mathrm{hr}$ before to $4 \mathrm{hr}$ after the intraduodenal administration of micellar solutions, then $1 \mathrm{mg} / \mathrm{hr}$ at $\mathrm{hr} 5$ and 6 . The absorption of these two fatty acids are shown as the values of radioactivity in intestinal lymph from control and puromycin-treated animals.

And the total recovery of administered $[1-14 \mathrm{C}]$ linoleic acid was reduced in colchicine-treated animals to $51 \%$ compared with $87 \%$ in control animals $(\mathrm{P}<0.001$, $t=6.67$ ). In case of palmitic acid absorption, the lymphatic appearance of [1-14 C]palmitic acid by $90 \mathrm{~min}$ was also reduced to $20 \%$ compared with $43 \%$ in controls $(0.01<\mathrm{P}<0.02, \mathrm{t}=3.60)$ and the total recovery over the $6 \mathrm{hr}$ period was also reduced to $46 \%$ compared with $68 \%$ in controls $(0.001<\mathrm{P}<0.005$, $t=4.43$ ). The degree of inhibition between two kind of long chain fatty acid was considered to be not significantly different when colchicine was treated. The absorptive peak of radioactivity was found at the first $30-60 \mathrm{~min}$ after the administration of linoleic acid as well as palmitic acid micelles to control aniamls. Colchicine-treated animals, however, demonstrated a delayed peak of absorption shifting to $60-90 \mathrm{~min}$ and significant amount of radioactivity counting to 

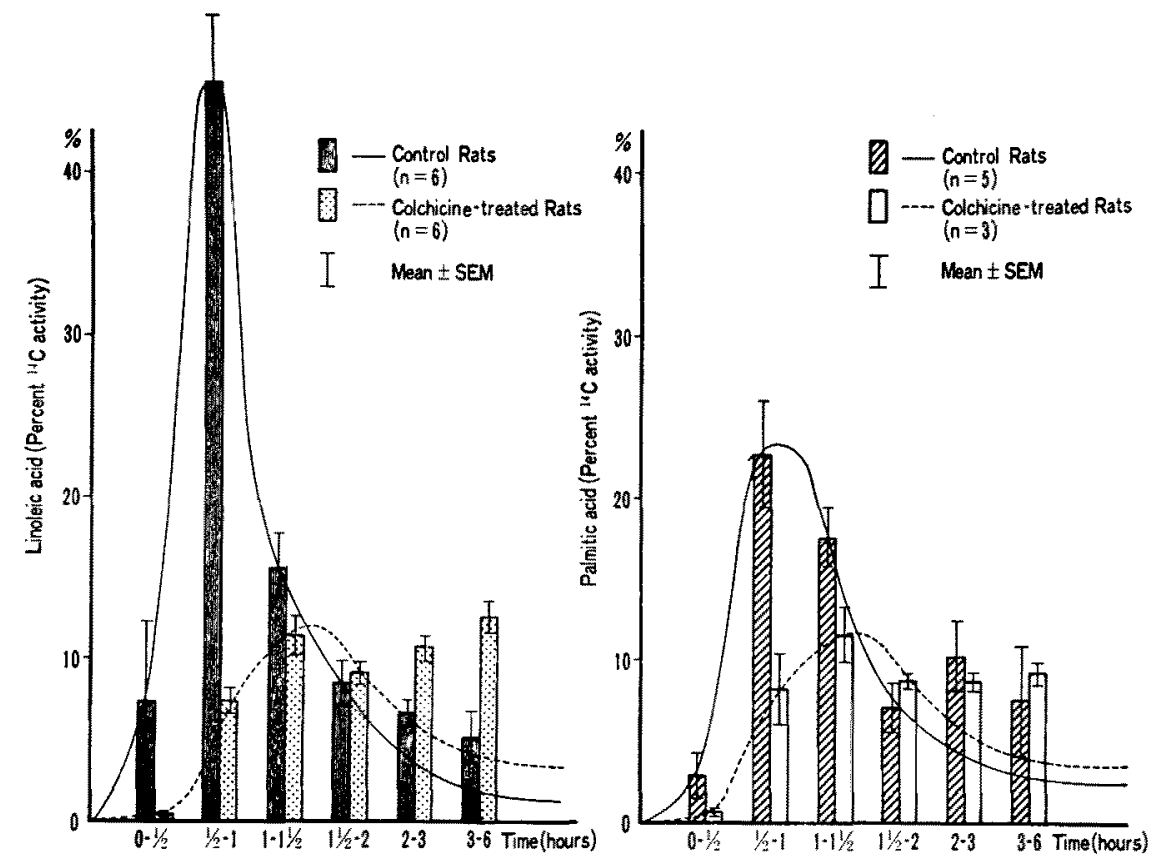

Fig. 4 Effect of colchicine on the lymphatic absorption of $[1-14 \mathrm{C}]$ linoleic acid (left half) and $\left[1{ }^{14} \mathrm{C}\right]$ palmitic acid (right half). Colchicine $(0.5 \mathrm{mg} / \mathrm{kg}$ ) was administered intraperitoneally $2 \mathrm{hr}$ before the intraduodenal infusion of micellar solutions of $\left[1^{-14} \mathrm{C}\right]$ linoleic acid and $[1-14 \mathrm{C}]$ palmitic acid. The absorption of these two fatty acids are shown as the values of radioactivity in intestinal lymph from control and colchicine-treated animals.

appear as late as $6 \mathrm{hr}$ after the lipid administration.

\section{DISCUSSION}

This study was designed to compare the metabolic differences between unsaturated and saturated long chain fatty acids in the process of lipoprotein formation and lipoprotein release during the lipid absorption from small intestine.

In control animals, the lymphatic absorption of linoleic acid is more rapidly than the absorption of palmitic acid. Fernandes et al..$^{9}$ already observed that in patients with Celiac disease the absorption of unsaturated fatty acid was more rapidly than the saturated one. The process of intestinal absorption of long chain fatty acid is complicated and is now established that, ${ }^{1}$ following uptake by the absorptive cells, they are reesterified before the formation of triglyceride 
rich lipoproteins. Linoleic acid and palmitic acid differ markedly in regard to several physical properties, therefore, it is easily supposed that the intestinal absorption reflecting their physical properties could account for the observed differences in lymphatic absorption. However the exact site of difference in the process of lipid absorption and transportation from intestinal lumen to lymphatics has not been clearly delineated. Ockner reported ${ }^{10}$ utilizing rat everted sacs that although uptake of palmitate equalled or exceeded that of linoleate, palmitate esterification was significantly less rapid than that of linoleate. It is conceivable that aside from the phase of reesterification, other factors such as the phase of lipoprotein formation or lymphatic secretion of lipoprotein will be likely attributable to the difference of absorption of these two long chain fatty acids.

In the present study using puromycin, an inhibitor of protein synthesis which may block the lipoprotein formation in the intestinal epithelial cells, ${ }^{11}$ the remarkable decrease in lymphatic absorption of linoleic acid was observed, although palmitic acid absorption was not significantly inhibited. Recently, in the electron microscopic study of lipoproteins which enter lymph during the absorption of exogenous long chain fatty acids, it was observed 14,15 that the characteristics of the lipoprotein particles was different between unsaturated and saturated long chain fatty acid. During unsaturated fat absorption, lymph lipoprotein particle have the characteristics of chylomicrons, while during saturated fat absorption, lymph lipoproteins are similar to very low density lipoproteins (VLDL). Therefore we supposed that puromycin will mainly inhibit the formation of chylomicron rich lipoprotein from linoleic acid, whereas puromycin has a small effect on the formation of VLDL rich lipoprotein from palmitic acid. These difference of puromycin inhibition may account for the apoprotein composition of two lipoproteins, of which turnover time will differ each other. However, there is also a possibility that the effect of puromycin inhibition may exist in any other phases in addition to lipoprotein formation, such as intracellular carrying ${ }^{16}$ or reesterification of fatty acid. Further studies will be necessary to elucidate the difference of two fatty acids in these processes.

We also tried to assess the difference between two different kind of fatty acid in another process of intestinal absorption, namely the process of lipoprotein secretion from intestinal absorptive cells. Colchicine, an inhibitor of microtubular function, ${ }^{17}$ is known to cause severe diarrhoea during medication. In recent studies $^{9,18}$ it has been demonstrated that impairment of lipid transport was induced by colchicine, and that colchicine caused the diminished secretion of synthesized lipoprotein particles from intestinal cells to lymph. Therefore, the difference between two fatty acids in the effect of colchicine on the process of lipoprotein release was examined. In the present study, the previous administra- 
tion of colchicine caused a delay and decrease in the lymphatic absorption of intraduodenally administered linoleic acid. Unlike studies utilizing puromycin which resulted impaired apoprotein synthesis, ${ }^{19}$ colchicine caused a delayed and decreased lymphatic absorption in case of palmitic acid as well as linoleic acid. The degree of inhibition was not significantly different between two long chain fatty acids.

In conclusion, we consider that the difference of lymphatic absorption of linoleic acid and palmitic acid will be mainly caused from the phase of lipoprotein formation during lipid absorption and the phase of lipoprotein secretion will not be attributable.

\section{ACKNOWLEDGEMENT}

This study was supported by the Research Grant from Ministry of Health and Welfare of Japan.

\section{REFERENCES}

1. Gangl, A. and Ockner, R. K.: Intestinal metabolism of lipids and lipoproteins. Gastroenterology, 68: 167-186, 1975

2. Asakura, H., Miura, S., Morishita, T. et al.: Endoscopic approach to proteinlosing enteropthy. In "Topics in digestive endoscopic examination" edited by Takemoto, T., and Kawai, K. Igaku-tosho-shuppan Co, Tokyo, 1978, 378-385 (in Japanese)

3. Asakura, H., Morita, A., Morishita, T. and Tsuchiya, M.: Pathophysiology of the small intestine. Stomach and Intestine, 11: 175-186, 1976

4. Linscheer, W. G., Malagelada, J. R. and Fishman, W. H.: Diminished oleic acid absorption in man by L-phenylalanine inhibition of an intestinal phosphohydrolase. Nature (London), New Biol., 231: 116-117, 1971

5. Salt, H. B., Wolff, O.H., Lloyd, J.K. et al.: On having no beta-lipoprotein. A syndrome comprising a-betalipoproteinemia, acanthocytosis and steatorrhoea. Lancet, 2: $325-329,1960$

6. Glickman, R.M., Kirsch, K. and Isselbacher, K. J.: Fat absorption during inhibition of protein synthesis: studies of lymph chylomicrons. J. Clin. Invest., 51: 356-363, 1972

7. Glickman, R.M., Perrotto, J.L. and Kirsch, K.: Intestinal lipoprotein formation: Effect of colchicine. Gastroenterology, 70: 347-352, 1976

8. Shimoyama, T., Kikuchi, H., Press, M. et al.: Fatty acid composition of plasma lipoproteins in control subjects and in patients with malabsorption. Gut, 14: 716722,1973

9. Fernandes, J., Van de Kamer, J.H. and Weijers, H. A.: Differences in absorption of the various fatty acids studied in children with steatorrhea. J. Clin. Invest., 41: 488-494, 1962

10. Ockner, R. K., Pittman, J.P. and Yager, J. L.: Differences in the intestinal absorption of saturated and unsaturated long chain fatty acids. Gastroenterology, 62: 981-992, 1972

11. Sabesin, S. M. and Isselbacher, K. J.: Protein synthesis inhibition: Mechanism for 
the production of impaired fat absorption. Science, 147: 1149-1151, 1965

12. Bollman, J. L.: A cage which limits the activity of rats. J. Lab. Clin. Med., 33: 1348, 1948

13. Johnston, J.M. and Borgström, B.: The intestinal absorption and metabolism of micellar solutions of lipids. Biochim. Biophys. Acta, 84: 412-423, 1964

14. Ockner, R. K., Hughes, F. B. and Isselbacher, K. J.: Very low density lipoproteins in intestinal lymph: Role in triglyceride and cholesterol transport during fat absorption. J. Clin. Invest., 48: 2367-2373, 1969

15. Ockner, R. K. and Jones, A. L.: An electron microscopic and functional study of very low density lipoproteins in intestinal lymph. J. Lipid Res., 11: 284-292, 1970

16. Ockner, R. K., Manning, J. A., Poppenhausen, R. B. et al.: A binding protein for fatty acids in cytosol of intestinal mucosa, liver, myocardium, and other tissues. Science, 177: 56-58, 1972

17. Borisy, G. G. and Taylor, E. W.: The mechanism of action of colchicine. Binding of colchicine- ${ }^{3} \mathrm{H}$ to cellular protein. J. Cell. Biol., 34: 525-533, 1967

18. Arreaza-plaza, C. A., Bosch, V. and Otayek, M. A.: Lipid transport across the intestinal epithelial cell. Effect of colchicine. Biochim. Biophys. Acta, 431: 297302, 1976

19. Glickman, R. M. and Kirsch, K.: Lymph chylomicron formation during the inhibition of protein synthesis. Studies of chylomicron apoproteins. J. Clin. Invest., 52: $2910-2920,1973$ 